\section{Kidney \\ Blood Pressure Research}

Kidney Blood Press Res 2015;40:542-554

DOI: $10.1159 / 000368530$

Published online: October 26, 2015

Accepted: September 21, 2015

(C) 2015 S. Karger AG, Basel

www.karger.com/kbr

1423-0143/15/0405-0542\$39.50/0

This is an Open Access article licensed under the terms of the Creative Commons AttributionNonCommercial 3.0 Unported license (CC BY-NC) (www.karger.com/OA-license), applicable to the online version of the article only. Distribution permitted for non-commercial purposes only.

\title{
Comparative Effect of a Renin Inhibitor and a Thiazide Diuretic on Renal Tissue Oxygenation in Hypertensive Patients
}

\author{
Nima Vakilzadeh Marie-Eve Muller Valentina Forni Bastien Milani \\ Lucie Hoffman Maciej Piskunowicz Marc Maillard Carole Zweiacker \\ Menno Pruijm Michel Burnier
}

Service of Nephrology and Hypertension, CHUV, University Hospital Lausanne, Switzerland

\author{
Key Words \\ Renal $•$ Renin inhibition $\cdot$ Diuretics $•$ Human hypertension $•$ BOLD-MRI $•$ Oxygenation
}

\begin{abstract}
Background/Aims: The purpose of the present study was to compare the direct renin inhibitor aliskiren to the diuretic hydrochlorothiazide (HCTZ) in their ability to modulate renal tissue oxygenation in hypertensive patients. Methods: 24 patients were enrolled in this randomized prospective study and 20 completed the protocol. Patients were randomly assigned to receive either aliskiren 150-300 mg/d or HCTZ 12.5 - 25 mg/d for 8 weeks. Renal oxygenation was measured by BOLD-MRI at weeks 0 and 8 . BOLD-MRI was also performed before and after an i.v. injection of $20 \mathrm{mg}$ furosemide at week 0 and at week 8. BOLD-MRI data were analyzed by measuring the oxygenation in 12 computed layers of the kidney enabling to asses renal oxygenation according to the depth within the kidney and by the classical method of regions of interest (ROI). Results: The classical ROI analysis of the data showed no difference between the groups at week 8 . The analysis of renal oxygenation according to the 12 layers method shows no significant difference between aliskiren and HCTZ at week 8 before administration of furosemide. However, within group analyses show that aliskiren slightly but not significantly increased oxygenation in the cortex and decreased medullary oxygenation whereas HCTZ induced a significant overall decrease in renal tissue oxygenation. With the same method of analysis we observed that the response to furosemide was unchanged in the HCTZ group at week 8 but was characterized by an increase in both cortical and medullary oxygenation in aliskiren-treated patients. Patients responding to aliskiren and HCTZ by a fall in systolic blood pressure of $>10 \mathrm{mmHg}$ improved their renal tissue oxygenation when compared to nonresponders. Conclusion: With the classical method of evaluation using regions no difference were found between aliskiren and HCTZ on renal tissue oxygenation after 8 weeks. In contrast, with our new method that takes into account the entire kidney, within group analyses show that aliskiren slightly increases cortical and medullary renal tissue oxygenation in hypertensive patients whereas HCTZ decreases significantly renal oxygenation at trough.
\end{abstract}

ClinicalTrial.gov Identifier: NCT01519635

Copyright @ 2015 S. Karger AG, Basel

Prof. Michel Burnier

Service of Nephrology and Hypertension, CHUV, Rue du Bugnon 17, 1011 Lausanne

(Switzerland), Tel. +41 2131411 54, E-Mail michel.burnier@chuv.ch 


\section{Kidney Blood Pressure Research}

Kidney Blood Press Res 2015;40:542-554

\begin{tabular}{l|l}
\hline DOI: $10.1159 / 000368530$ & (C) 2015 S. Karger AG, Basel
\end{tabular}

Published online: October 26, 2015

www.karger.com/kbr

Vakilzadeh/Muller/Forni/Milani/Hoffman/Piskunowicz/Maillard/Zweiacker/Pruijm/ Burnier: Renin Inhibition and Renal Oxygenation

\section{Introduction}

Hypertension is both a major cause of end stage renal disease and an important risk factor for the progressive decline in renal function in patients suffering from renal diseases [1-3]. In most developed countries hypertension accounts for approximately $30 \%$ of patients entering a dialysis or transplantation program. The deleterious effect of hypertension on renal function is mediated by several pathogenic mechanisms including an increase in intraglomerular pressure, endothelial dysfunction, inflammation, oxidative stress and proteinuria. The renin-angiotensin system (RAS) plays an important role in mediating many of these mechanisms as angiotensin II has been shown to increase intraglomerular pressure, and proteinuria but also to promote inflammation, extracellular matrix accumulation and cellular proliferation [4, 5] Angiotensin II has also been found to reduce acutely cortical oxygenation by reducing cortical flow in humans, a finding that may contribute to the development of tissue fibrosis [6]. Angiotensin II has also a major impact on medullary blood flow and this may play an important role in the pathogenesis of hypertension. Indeed, a sustained angiotensin II-mediated reduction of medullary blood flow and the oxidative stress induced by an activation of the RAS have been associated with medullary ischemia and the development of salt-sensitive hypertension in animals [7-9]. Thus, the ability to measure renal tissue oxygenation and the impact of drugs affecting the RAS or renal sodium transport may be of interest to explore the pathogenesis of hypertension.

For several decades, non-invasive measurements of renal tissue oxygenation were not available. Hence several hypotheses linking hypoxia-induced renal lesions with hypertension or renal diseases progression could not be verified in humans. Nowadays, blood oxygenation-level dependent MRI (BOLD-MRI) enables a non-invasive assessment of renal tissue oxygenation in animals and humans, high R2* values corresponding to low tissue oxygenation [10-17]. With this new approach several studies have been conducted in patients with hypertension and/or CKD and so far discrepant results have been reported [18]. In essential hypertension, for example, Textor et al found an increase in medullary R2* values in African-American hypertensive patients in comparison to white hypertensives indeed suggesting medullary hypoxia in African Americans but not in Whites [19]. Reduced renal oxygenation has also been found in the acute phase of renovascular hypertension but normal oxygenation levels were found beyond the stenosis later on, an observation which suggests an adaptation of tissue oxygenation despite the chronic reduction of renal blood flow. Besides, only severely stenotic kidneys exhibit a marked hypoxia [20,21]. Pruijm et al. did not find any difference in cortical or medullary R2* signal between healthy volunteers and treated hypertensive patients suggesting that renal tissue oxygenation is relatively well maintained in hypertensive patients [22].

Drugs actually recommended as first line therapy of hypertension include blockers of the renin-angiotensin system, calcium antagonists and diuretics [23]. Today there is still limited information on the effect of these drugs classes on renal tissue oxygenation in hypertensive patients. In a first cross-over study, we have investigated in diabetic hypertensive patients the ability of the angiotensin converting enzyme inhibitor enalapril and the angiotensin II receptor blocker candesartan to chronically improve renal tissue oxygenation [24]. In this study, neither enalapril nor candesartan administered for one month modified cortical or medullary R2* suggesting no sustained effect on renal oxygenation. In hypertensive patients with renal impairment, acute administration of olmesartan has been reported to increase tissue oxygenation, an effect which was not found in healthy controls [25]. Similar acute changes in renal oxygenation were reported on small group of patients receiving captopril or losartan $[26,27]$. 


\section{Kidney Blood Pressure Research}

Kidney Blood Press Res 2015;40:542-554

\begin{tabular}{l|l}
\hline DOI: $10.1159 / 000368530$ & (C) 2015 S. Karger AG, Basel
\end{tabular}

Published online: October 26, 2015

www.karger.com/kbr

The consumption of oxygen by the kidney is linked predominantly to the reabsorption of sodium [28, 29]. Thurau et al showed in the 1960s already that the administration of a thiazide diuretic diminished sodium reabsorption and hence reduced renal oxygen consumption in dogs [30]. However, no such data exist with thiazide diuretics in humans. In healthy subjects and hypertensive patients reducing dietary salt intake has been found to improve renal oxygenation thus confirming the link between sodium transport and renal oxygen utilization [31]. More data are available with furosemide which markedly increases renal oxygenation by inhibiting sodium transport in the loop of Henle [20]. Today, furosemide is used as a functional test by many groups performing BOLD-MRI. In hypertensive patients receiving $40 \mathrm{mg}$ of furosemide chronically, baseline cortex and medullary R2* were not different from furosemide naive patients suggesting no long-term effect of this diuretic on renal tissue oxygenation [32]. However, the acute response to furosemide $20 \mathrm{mg}$ was significantly blunted in patients using furosemide chronically [32].

Since thiazides are the most prescribed diuretic in hypertension mainly in association with a blocker of the renin-angiotensin system, we designed a randomized prospective parallel group study to compare the effects of the renin inhibitor aliskiren and the diuretic hydrochlorothiazide (HCTZ) on renal tissue oxygenation measured by BOLD-MRI in patients with essential hypertension. In contrast to previous studies, BOLD-MRI images were analyzed using the region of interest (ROI) technique and also with the new "onion peel" technique [33] enabling to evaluate the entire kidney using 6 or 12 layers as will be described below. In brief, with the onion peel technique, the kidney cortex and medulla are defined manually excluding the pelvis and the calyxes and this enables to define two boundaries: the external one corresponding to the cortical side and the internal one corresponding to the medullary side. Thus one can obtain several measurements at different depths which correspond either to the cortex (superficial depths) or to the medulla (deep depths) or a combination of both (intermediate depths). This approach was recently tested with a segmentation of the kidney parenchyma in 6 equal layers and compared with the classical ROI-technique. We found this new analytic method to be more reproducible with less inter-operator variability than the classical ROI method [33]. In addition, increasing the number of layers from 6 to 12 improves the accuracy and the ability to distinguish the various components of the kidney mainly the cortex and the medulla. Inter-observer reproducibility with the 12 layer analysis was comparable to the results obtained with the six-layer technique.

\section{Patients and Methods}

This was a single center study and all patients were recruited in the outpatient clinic of the Nephrology and Hypertension division at the University Hospital of Lausanne. Patients with essential hypertension stage 1 and 2 were enrolled. Patients excluded from the study were those with: secondary forms of hypertension, a serum potassium $>5.0 \mathrm{mmol} / \mathrm{l}$ or $<3.5 \mathrm{mmol} / \mathrm{l}$, a treatment of aliskiren or aldosterone antagonists, an intolerance to aliskiren or hydrochlorothiazide, a contra-indication to furosemide, an inability to understand the protocol for any reason, severe psychiatric illness, severe asthma and contra-indications to MR-imaging such as claustrophobia or presence of an implanted metallic device. Women with childbearing potential without any effective contraception and expectant mothers (positive pregnancy test) were not enrolled. After explaining the nature and purpose of the study, written informed consent was obtained from each patient. The protocol was approved by the local institutional review committee (Ethical Committee of the Canton de Vaud, Switzerland).

\section{Study protocol}

Once patients had accepted to participate and signed the informed consent, a complete physical examination was performed. Blood pressure (BP) was measured three times at baseline and at each visit using the validated automated Omron 705IT oscillometric device. After a two-week wash-out period during 


\section{Kidney \\ Blood Pressure Research}

Kidney Blood Press Res 2015;40:542-554

\begin{tabular}{l|l}
\hline DOI: $10.1159 / 000368530$ & (C) 2015 S. Karger AG, Basel
\end{tabular}

Published online: October 26, 2015

www.karger.com/kbr

Vakilzadeh/Muller/Forni/Milani/Hoffman/Piskunowicz/Maillard/Zweiacker/Pruijm/ Burnier: Renin Inhibition and Renal Oxygenation

which RAS blockers and diuretics were withdrawn, patients were randomized to receive either aliskiren $150 \mathrm{mg}$ od or HCTZ $12.5 \mathrm{mg}$ od according to a single-blind study design. After 2 weeks of treatment, drug doses were up-titrated to $300 \mathrm{mg}$ and $25 \mathrm{mg}$ od respectively if treatments were well tolerated. All patients were treated for 8 weeks. All concomitant medications (including beta-blockers and calcium antagonists) were continued throughout the study, yet no change in dosing were allowed and no new therapy could be introduced unless absolutely necessary. Drug adherence was monitored by pill count at the end of the study.

During the study patients were seen every two weeks. BP and heart rate were measured at each term. Two BOLD-MRI measurements were performed in each participant: one at baseline and a second one at 8 weeks. During the study, participants were maintained on their regular diet. Dietary sodium intake was kept as stable as possible, because salt intake has been shown to influence the R2* signal [31]. Salt intake was verified each time before BOLD-MRI using a $24 \mathrm{~h}$ urine collection. BOLD-MRI was performed as described previously [22]. In brief, patients were asked to come to the unit at 7:30 am, a light breakfast before arrival was tolerated. An identical oral hydration protocol was followed by each participant: a load of $3 \mathrm{ml} / \mathrm{kg}$ of water at arrival, followed by $1 \mathrm{ml} / \mathrm{kg} / \mathrm{h}$ oral water administration, in order to avoid as much as possible differences in renal perfusion induced by differences in volume status. Upon arrival, an intravenous catheter was inserted into an antecubital vein. Thirty minutes later blood was drawn to measure serum sodium, potassium and glucose, creatinine, blood urea nitrogen and hemoglobin as described previously. During the morning each patient underwent a sinistrin (equivalent of inulin) and para-amino-hippurate (PAH) clearance measurement to assess glomerular filtration rate and renal plasma flow as described previously [34]. Two 30 minutes urine collections were obtained before the BOLD-MRI to measure proximal sodium reabsorption using the endogenous lithium technique and calculation of the fractional excretion of lithium as described previously [34]. BOLD-MRI acquisition was performed at $1 \mathrm{pm}$ before and $15 \mathrm{~min}$ after the injection of $20 \mathrm{mg}$ of furosemide. Measurements were done at trough e.i. 28 to $30 \mathrm{~h}$ after the last dose on week 8 .

\section{Acquisition and analysis of BOLD-MRI images}

Magnetic resonance (MR) images were acquired using four coronal slices on a 3T-whole-body MR system (Magnetom Prisma, Siemens Medical Systems, Erlangen, Germany). Twelve $\mathrm{T}_{2}{ }^{*}$-weighted images were recorded for each coronal slice within a single breath-hold of 16.6 seconds (in expiration) with a modified Multi Echo Data Image Combination sequence (MEDIC) for BOLD analysis with the following parameters: repetition time (TR) $65 \mathrm{~ms}$, echo time (TE) 6-52.2 ms (equidistant echo time spacing of $4.2 \mathrm{~ms}$ ), radiofrequency excitation angle $30^{\circ}$, field of view (FOV) $400 \times 400 \mathrm{~mm}^{2}$, voxel size 0.8 × $0.8 \times 5 \mathrm{~mm}^{3}$, slice thickness $5 \mathrm{~mm}$, slice distance $5.5 \mathrm{~mm}$, bandwidth $331 \mathrm{~Hz} /$ pixel, matrix 256x256 (interpolated to 512x512).

The analysis of MR images was done using the classical regions of interest method and the recently developed concentric objects or "onion peel" technique as mentioned earlier [33]. This technique enables to define two boundaries: the external one corresponding to the cortical side and the internal one corresponding to the medullary side. The depth between the external and internal boundary can be expressed as a percent of the total parenchymal thickness, the external boundary being at depth $0 \%$ and the internal boundary at depth $100 \%$. The size of each layer depends of kidney size and volume and averages $1.43 \pm 0.15 \mathrm{~mm}$ or $1.8 \pm 0.2$ pixels (mean $\pm \mathrm{SD}, \mathrm{n}=40$ ) in normal size kidneys. Longitudinal curves can be computed throughout the kidney at any fixed depth with a mean R2* value for each level of depth. In this study, the analysis of the radial R2* distribution was computed to obtain 13 numerically computed longitudinal curves at equally spaced depths from $0 \%$ to $100 \%$. This technique enables to represent data as a curve relating the R2* on the $\mathrm{Y}$ axis and the depth inside de kidney as $\mathrm{X}$ axis. Depths $0-30 \%$ correspond mainly to cortical tissue and those between $60-100 \%$ to medullary tissue as discussed previously [33]. The precise definition of the medullary tissue which contains the loop of Henle, the vasa recta, and the collecting tubules, is difficult as there is a transition between cortex and medulla and the site of this transition is not always at the same depth within the kidney. However, depths 80 to $100 \%$ are more likely to include only medullary tissue. The pelvis is not included in the layers.

Figure 1 shows on the left the classical ROI technique and the new approach with a computed segmentation of the kidney in 12 layers with equally spaced depths. R2* values were fitted for each pixel by a linear-least-square-of-log algorithm and values smaller than $10 \mathrm{~Hz}$ and bigger than $50 \mathrm{~Hz}$ were excluded. 


\section{Kidney Blood Pressure Research}

Fig. 1. Illustration of the region of interest (ROI) and the «onion peel» techniques used to asses renal tissue oxygenation in humans. With the ROI technique (A), regions are defined manually within the cortex and medullary and an analysis is done on these regions uniquely. With
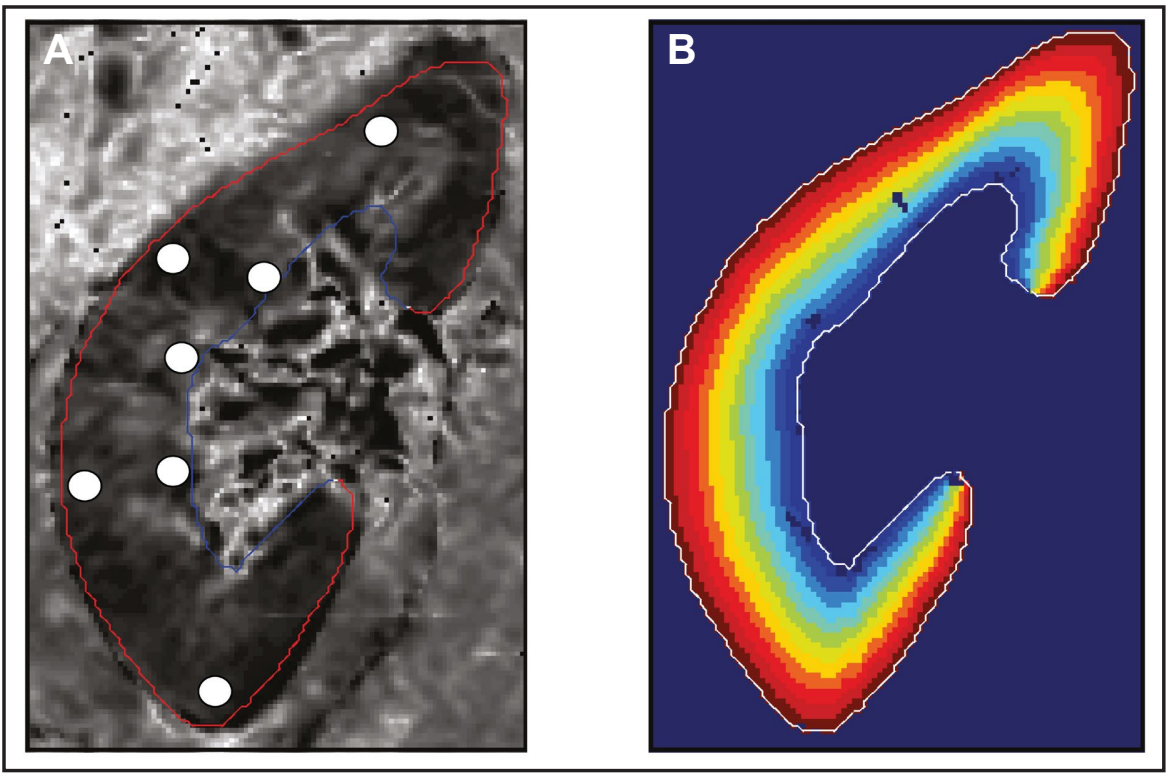
onion peel technique (B) (here: whole kidney, cortex + medulla), the outer and inner boundaries are defined manually but then 12 layers are defined by the computer program and analyses are performed on the entire layers are different depths.

Cysts were excluded by a manual segmentation. We also calculated the response to furosemide with this technique. In that case the furosemide-induced change in R2* (delta R2*) is correlated to the depths. Note that a positive value of delta $\mathrm{R} 2 *$ with this representation corresponds to an increase in renal oxygenation whereas in other figures a increase in R2* corresponds to a decrease in renal tissue oxygenation and vice versa. We also assessed the effect of drugs on the cortical/medullary ratio as the mean R2* value in cortical layers (depths $0-30 \%$ ) divided by the mean R2* value in medullary layers (depths 70-100\%). In order to increase the readability, the terms 'oxygenation' and renal R2* levels are used interchangeable in this study.

\section{Statistics}

The randomization list was generated by computer. STATA 12 was used for statistical analysis. The R2* values corresponding to renal deoxyhemoglobin content were expressed as means \pm standard deviation (SD) or standard error of the mean (SEM) for cortex and medulla separately. Differences between groups were calculated with Student's t-test and Wilcoxon rank sum test whenever appropriate. Within group differences were evaluated using a paired t-test. $P$ values below 0.05 were considered as significant.

Based on an expected medication-induced difference in renal oxygenation (as expressed by R2*) of $10 \%$, an alpha of 0.05 at two sided significance level, and using the highest standard deviation obtained in former studies [22,31] we calculated that we needed to include 12 patients in each group to have a power of $80 \%$ and 15 patients in each group to have a power of $90 \%$. Strength association between two quantitative variables was estimated with the Pearson correlation coefficient.

\section{Results}

\section{Baseline characteristics of the patients}

Forty seven hypertensive patients were screened. Twenty four patients fulfilled inclusion criteria and were enrolled but 4 patients had to be excluded because of the lack of adequate venous access or for other reasons. Thus 20 patients completed the study, 11 were randomized to aliskiren and 9 to HCTZ. As shown in Table 1 more patients of the aliskiren group were 


\section{Kidney Blood Pressure Research}

under statins (respectively $81.8 \%$ in the aliskiren group and $\quad 33.3 \%$ in the HCTZ group, $\mathrm{p}<0.05$ ) but none of the other parameters were significantly different between groups at baseline. In the aliskiren group, 3 patients were on atenolol and 1 on metopro-
Table 1. General clinical characteristics of the patients

\begin{tabular}{lccc}
\hline & ALISKIREN & HCTZ & P value \\
\hline $\mathrm{N}$ & 11 & 9 & \\
\hline Age (years) & $55.7(8.6)$ & $49.7(15.7)$ & $\mathrm{NS}$ \\
Sex ratio (males/females) & $8 / 3$ & $6 / 3$ & $\mathrm{NS}$ \\
Caucasian (\%) & 100 & 88.9 & $\mathrm{NS}$ \\
BMI (kg/m²) & $31.0(5.3)$ & $27.7(3.9)$ & $\mathrm{NS}$ \\
Diabetes (\%) & 18.2 & 11.1 & $\mathrm{NS}$ \\
Baseline systolic blood pressure (mmHg) & $150(10.7)$ & $141(12.9)$ & $\mathrm{NS}$ \\
Baseline diastolic blood pressure (mmHg) & $83(9.2)$ & $83(7.1)$ & $\mathrm{NS}$ \\
Glycate hemoglobin HbA1C (\%) & $5.8(0.4)$ & $5.6(0.6)$ & $\mathrm{NS}$ \\
Number of antihypertensive drugs (n) & $1.5(1.3)$ & $1.3(1.6)$ & $\mathrm{NS}$ \\
Beta-blockers (\%) & 36.4 & 22.2 & $\mathrm{NS}$ \\
Calcium channel blockers (\%) & 18.2 & 22.2 & $\mathrm{NS}$ \\
Active Smoker (\%) & $12.3(21.2)$ & $13.0(16.2)$ & $\mathrm{NS}$ \\
Dyslipidemia or statin treatment (\%) & 81.8 & 33.3 & 0.05 \\
Coronary artery disease (\%) & 36.4 & 11.1 & $\mathrm{NS}$ \\
\hline
\end{tabular}

Variables are shown as mean \pm SD or as percentage of total number of patients as appropriate

Table 2. Clinical and biological parameters in the two treatment groups at baseline and after 8 weeks of treatment

\begin{tabular}{|c|c|c|c|c|}
\hline & \multicolumn{4}{|c|}{ Clinical parameters of patients } \\
\hline & $\begin{array}{c}\text { Aliskiren } \\
\text { baseline }\end{array}$ & HCTZ baseline & $\begin{array}{c}\text { Aliskiren } \\
\text { week } 8\end{array}$ & $\begin{array}{c}\text { HCTZ } \\
\text { week } 8\end{array}$ \\
\hline Systolic BP sitting (mmHg) & $151(10.7)$ & $142(12.9)$ & $139(19.7)$ & $136(14.6)$ \\
\hline Diastolic BP sitting (mmHg) & $84(9.2)$ & $83(7.1)$ & $77(9.4)$ & $81(9.9)$ \\
\hline Hearth rate sitting (beat/min) & $70(11.2)$ & $74(6.3)$ & $64(9.7) *$ & $73(9.1)$ \\
\hline Serum urea $(\mathrm{mmol} / \mathrm{l})$ & $5.2(1.5)$ & $4.9(1.2)$ & $5.1(1.0)$ & $4.8(0.9)$ \\
\hline Serum uric acid (mmol/l) & $352(77.0)$ & $336(50.7)$ & $363(78.6)$ & $382(34.9)$ \\
\hline Serum sodium (mmol/l) & $142(1.3)$ & $141(1.1)$ & $141(2.5)$ & $141(1.3)$ \\
\hline Serum potassium (mmol/l) & $3.9(0.2)$ & $4.0(0.2)$ & $4.0(0.2)$ & $3.7(0.2)^{*}$ \\
\hline Serum calcium corrected (mmol/l) & $2.2(0.1)$ & $2.2(0.1)$ & $2.2(0.1)$ & $2.2(0.1)$ \\
\hline Serum bicarbonates $(\mathrm{mmol} / \mathrm{l})$ & $27(0.7)$ & $27(0.2)$ & $25(1.6)$ & $30(2.8)$ \\
\hline Serum glucose $(\mathrm{mmol} / \mathrm{l})$ & $5.8(0.8)$ & $5.6(0.7)$ & $5.6(0.8)$ & $5.5(0.8)$ \\
\hline Serum creatinine $(\mu \mathrm{mol} / \mathrm{l})$ & $90(18.6)$ & $89(12.9)$ & $88(11.1)$ & $92(22.4)$ \\
\hline Serum Hemoglobin (g/l) & $136(11.6)$ & $144(11.4)$ & 139 (7.9) & $144(12.2)$ \\
\hline Sinistrin clearance $(\mathrm{ml} / \mathrm{min})$ & $105(22.2)$ & $97(10.2)$ & $90(20.5)$ & $99(28.0)$ \\
\hline Renal plasma flow (ml/min) & $512(166.5)$ & $467(92.9)$ & $454(115.0)$ & $424(77.7)$ \\
\hline Filtration fraction (\%) & $22.2(6.7)$ & $21.2(5.9)$ & $21.0(4.0)$ & $25.7(7.1)$ \\
\hline Salt consumption $(\mathrm{g} / 24 \mathrm{~h})$ & $10.2(6.0)$ & $9.3(5.2)$ & $8.6(3.6)$ & $12.3(5.6)$ \\
\hline $24 \mathrm{~h}$ urinary sodium (mmol) & $177(103.7)$ & $163(84.0)$ & $149(62.3)$ & $188(114.9)$ \\
\hline 24 hour urinary volume $(\mathrm{ml})$ & $1690(618)$ & $1386(390)$ & $1593(490)$ & $1548(523)$ \\
\hline
\end{tabular}

Variables are shown as mean \pm SD or percent(\%). ${ }^{*}$ Significant change at 2 month comparing to baseline $(p<0.05$-paired ttest or Wilcoxon Ranksum as appropriate). Electrolytes were measured 4 hours after hydratation protocol and after sinistrin and PAH administration. No significant difference in baseline clinical parameters between the two groups

lol and in the HCTZ group 1 one was on atenolol and another on metoprolol. Table 2 shows the biological characteristics of the patients at baseline and at the end of the study. Sitting heart rate decreased significantly in the aliskiren group (from 70 to 64 beats/min between baseline and week 8 ) and serum potassium decreased in the HCTZ group (from $4.0 \mathrm{mmol} / \mathrm{l}$ to $3.7 \mathrm{mmol} / \mathrm{l}$ ). Other variables were stable during the study. Note that BP decreased by $11 / 6 \mathrm{mmHg}$ (systolic/diastolic) after 8 weeks of aliskiren and by only $5 / 2 \mathrm{mmHg}$ with HCTZ. Because of the small number of patients, the difference did not reach statistical significance. Similarly, urinary sodium excretion decreased under aliskiren and increased with HCTZ at week 8. 


\section{Kidney \\ Blood Pressure \\ Research}

Kidney Blood Press Res 2015;40:542-554

\begin{tabular}{l|l}
\hline DOI: $10.1159 / 000368530$ & (c) 2015 S. Karger AG, Basel
\end{tabular}

Published online: October 26, 2015

www.karger.com $/ \mathrm{kbr}$

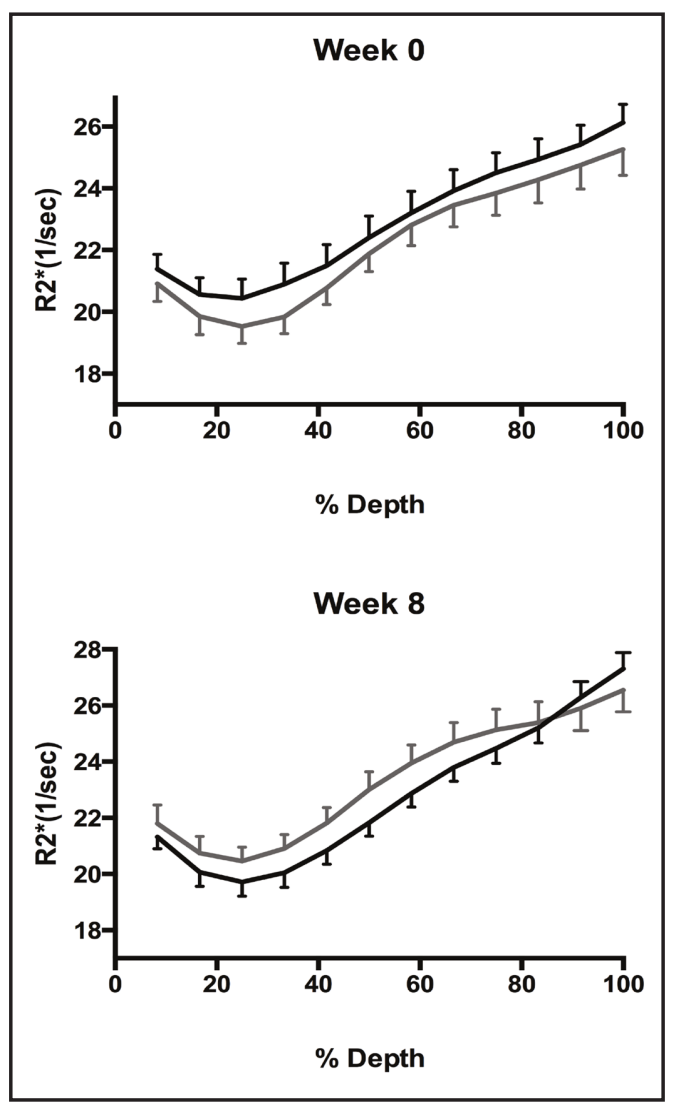

Fig. 2. R2* according to the depth within the kidney as measured by the onion peel technique in patients of the aliskiren (black lines) and HCTZ (grey lines) groups at week 0 (upper panel) and at week 8 (lower panel). Measurements were performed at week 0 and week 8 before the administration of furosemide. There was no significant difference between the two curves at week 0 as well as at week 8 . However, note the shift of the HCTZ curves over time.

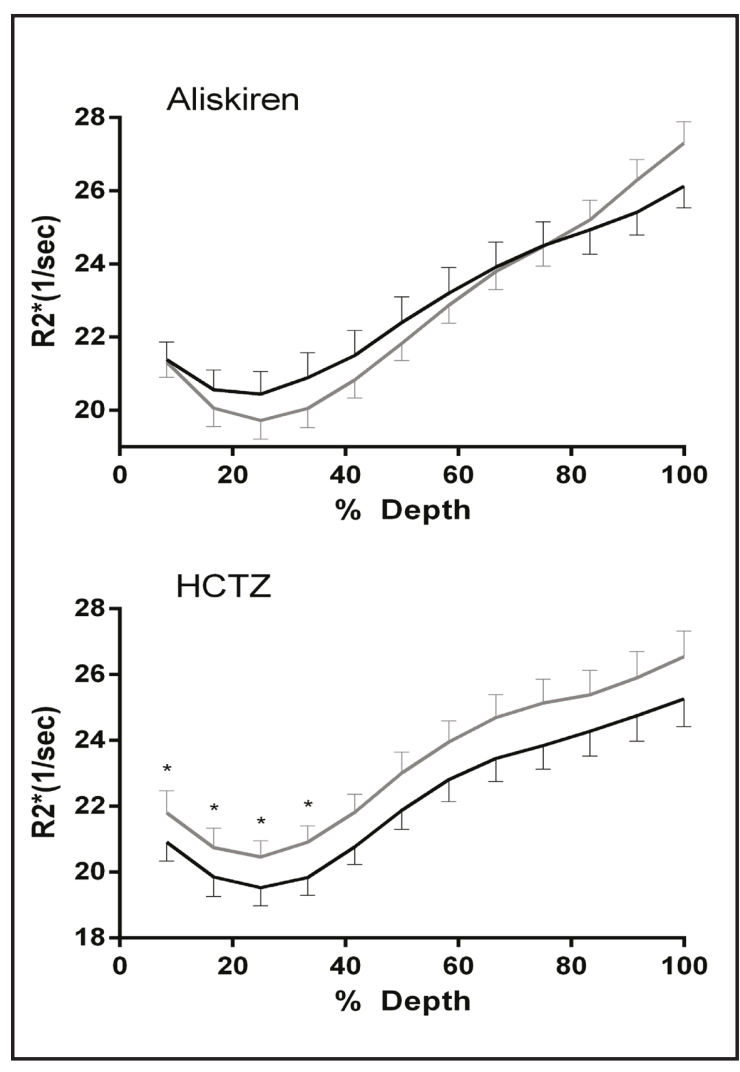

Fig. 3. Effect of aliskiren (upper panel) and HCTZ (lower panel) on R2* according to the depth within the kidney as measured by the onion peel technique. Measurements were performed at week 0 (black lines) and week 8 (grey lines) before the administration of furosemide. High $\mathrm{R} 2 *$ values correspond to a decrease and low values of $\mathrm{R} 2 *$ to an increase in renal oxygenation. Note the upward shift of the entire curve under HCTZ and the slight improvement in cortical oxygenation with aliskiren. Values are means \pm SEM. * $\mathrm{p}<0.05$.

When analyzing renal oxygenation curves at week 0 and at week 8 no significant difference was found between aliskiren and HCTZ with the region of interest method and the onion peel technique at baseline or pre- and post-furosemide (Figure 2 upper and lower panel). But, one can see that before starting the drugs at week 0 , renal oxygenation was slightly better in the HCTZ group and after 8 weeks the situation is reversed. However, with the 12 layer approach, some within group differences were observed that were not identified with the classical analysis. Thus, Figure 3 (upper panel) shows the changes in intrarenal R2* before and after administration of aliskiren as measured with the onion peel technique. At week 8, one observes a non-significant decrease in $\mathrm{R} 2 *$ in the cortex suggesting an improvement in cortical oxygenation (depth 0 to $30 \%$ ) and an increase in R2* in depths 80 to $100 \%$. Figure 3 (lower panel) shows the same profile for patients treated with HCTZ. In this figure one shows that the HCTZ curve at week 8 is entirely shifted to higher levels of R2* when compared to baseline (W0) suggesting an overall decrease in renal tissue oxygenation which is significant (versus baseline) in the surface layers reflecting the cortex. In line with this observation, the fractional excretion of lithium $\left(\mathrm{FE}_{\mathrm{Li}}\right)$ as a marker of proximal sodium 


\section{Kidney \\ Blood Pressure Research}

reabsorption remained stable in aliskiren-treated patients $(18 \pm 7.5 \%$ at $\mathrm{W} 0$ and $19.3 \pm 7.0$ at $\mathrm{W} 8, \mathrm{p}=\mathrm{ns}$ ) whereas in HCTZ-treated patients the $\mathrm{FE}_{\mathrm{Li}}$ decreased between $\mathrm{W} 0$ and $\mathrm{W} 8$ $\left(\mathrm{FE}_{\mathrm{Li}}: 21.2 \pm 9 \%\right.$ at $\mathrm{W} 0$ and $16.4 \pm 6.0 \%$ at $W 8, p=0.01$ ) indicating an increased proximal reabsorption of sodium.

Figure 4 (upper panel) shows the analysis of the changes in the response to furosemide (difference between pre and post furosemide) at week 0 and at week 8 in both groups. In aliskiren-treated patients, the furosemide administration is associated with an increase in cortical as well as medullary oxygenation. In the HCTZ group only a small nonsignificant decrease in cortical and increase in medullary oxygenation is observed (Figure 4, lower panel).

As decreases in BP may influence the impact of aliskiren and HCTZ on renal tissue oxygenation we analyzed the changes in cortical and medullary $\mathrm{R} 2 *$ in patients who lowered their BP by $>10 \mathrm{mmHg}$ systolic independently of the treatment modality (BP responders). Eight patients were considered as responders and 12 experienced small or no change in systolic BP. Interestingly a decrease in cortical $\mathrm{R} 2 *$ was found in responders suggesting an increase in oxygenation whereas in non-responders R2* increased (responders $-0.69 \pm 0.85$ sec- 1 versus $0.38 \pm 1.03 \mathrm{sec}-1$ in non-responders, $\mathrm{p}=0.03$ ). Figure 5 shows the correlation between the change in systolic $\mathrm{BP}$ and the change in cortical R2* between week 0 and week 8 before administration of furosemide. No significant difference in medullary R2* was observed between BP responders and non-responders. The cortical/medullary ratio significantly decreased in responders from $0.63 \pm 0.03$ at baseline to $0.60 \pm 0.03$ at week $8(p=0.01)$ and there was no change in cortical/ medullary R2* ratio in non-responders.

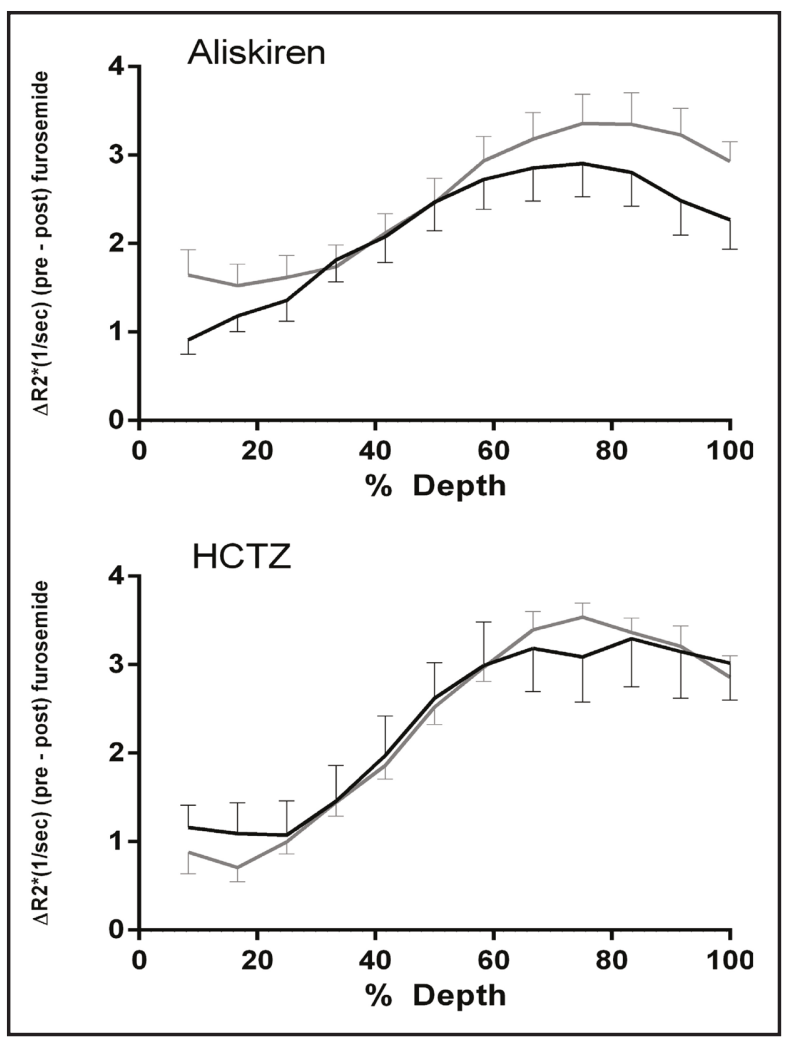

Fig. 4. Responses to furosemide (difference between pre and post-furosemide) at week 0 (black lines) and at week 8 (grey lines) in patients treated with aliskiren (upper panel) or HCTZ (lower panel). In this graph an increase in the change in $\mathrm{R}^{*}$ indicates an improvement in renal oxygenation. The response to aliskiren was improved at W8 whereas the response to HCTZ was unchanged. Data are means \pm SEM.

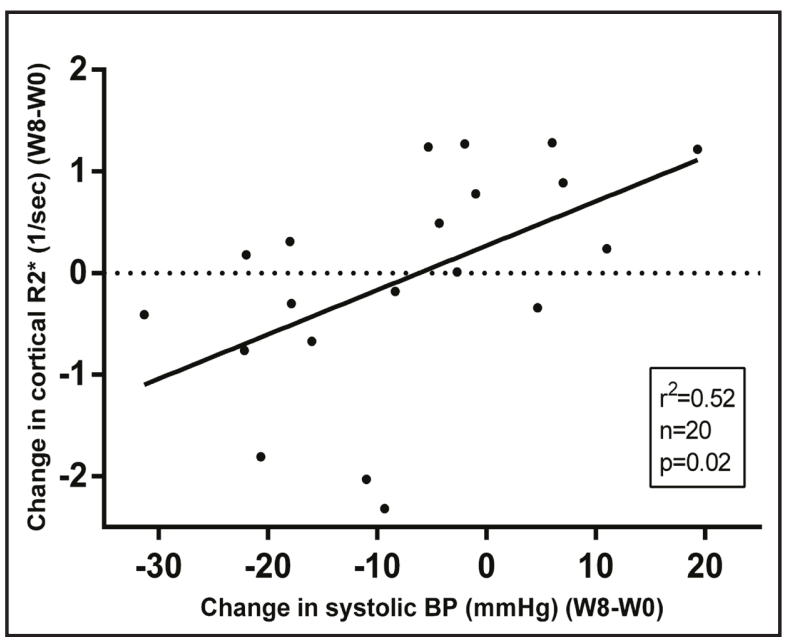

Fig. 5. Correlation between the changes in BP between week 0 and week 8 and the changes in cortical R2* between the same time period $(\mathrm{n}=20)$. 


\section{Kidney Blood Pressure Research}

Kidney Blood Press Res 2015;40:542-554

\begin{tabular}{l|l}
\hline DOI: $10.1159 / 000368530$ & (C) 2015 S. Karger AG, Basel
\end{tabular}

Published online: October 26, 2015

www.karger.com/kbr

\section{Discussion}

Taken together, the results of the present study show that renal cortical and medullary oxygenation as measured by BOLD MRI are not significantly different in hypertensive patients receiving the direct renin inhibitor aliskiren or HCTZ for 8 weeks when analysed using the classical regions of interest technique and the 12 layers approach. Yet, when assessed with the new analytic method taking into account the entire kidney, aliskiren appears to increase non-significantly cortical oxygenation and to lower medullary oxygenation at week 8 when compared to baseline suggesting a redistribution of the renal microcirculation or sites of sodium reabsorption. In contrast, HCTZ induces a significant overall decrease in renal oxygenation with entire upward shift of the curve. With both drugs the response to furosemide is preserved but the response is improved in aliskiren-treated but not in HCTZtreated patients. At last, in patients who responded to treatment by a fall in systolic BP of more than $10 \mathrm{mmHg}$, cortical oxygenation improved suggesting an impact of BP changes on renal cortex oxygenation.

Blockers of the renin-angiotensin system such as angiotensin converting enzyme (ACE) inhibitors or angiotensin II receptor blockers (ARB) are known to have favorable effects on renal function by lowering blood pressure and intraglomerular pressure but also by reducing proteinuria, increasing sodium excretion and lowering oxidative stress and inflammation [35]. Experimentally, blockade of the renin-angiotensin system has been found to improve renal tissue oxygenation [36]. However, whether an increase in renal oxygenation contributes to the clinical benefits of blockers of the renin-angiotensin system is not well demonstrated at least in humans. Indeed, contrasting results have been published so far regarding the effect of RAS blockers on renal tissue oxygen utilization. In humans, an acute administration of captopril has been reported to significantly change cortical/medullary $\mathrm{T} 2 *$ ratio in 5 patients with renal diseases but not in 5 healthy volunteers [26]. In another small group of 9 healthy subjects, Djamali et al. found an increase in cortical oxygenation after an acute administration of losartan [27]. The angiotensin II receptor blocker olmesartan was found to induce a 16\% increase in renal tissue oxygenation in patients with chronic kidney diseases but only a small number of patients were enrolled in this study [25]. Thus, many small studies suggest that blockade of the renin-angiotensin system has little if any impact on renal oxygenation in healthy subjects but tend to improve renal oxygenation in chronic kidney disease patients. In one of our previous study, neither candesartan nor enalapril were found previously to have a significant effect on cortex or medulla oxygenation in hypertensive patients with diabetic nephropathy [24]. So far, there are almost no data assessing the impact of a direct renin inhibitor on renal oxygenation except for a small study conducted in 5 CKD patients treated chronically with $300 \mathrm{mg}$ aliskiren [26].

This preliminary study found no change in cortical and renal medullary R2* but a decrease in cortical/medullary ratio. Thus, our study is the first to assess the effect of aliskiren on renal tissue oxygenation as measured with BOLD-MRI in hypertensive patients with an active control and a randomization process. In accordance with our previous observations with ACE inhibitors and ARBs, aliskiren does not appear to affect cortical or medullary tissue oxygenation after 8 weeks of treatment at least when compared with HCTZ and analyzed using the classical regions of interest method. However, when analyzing the changes between week 0 and week 8 within groups using a new method that includes the entire kidney, some aliskiren-induced changes in the distribution between cortex and medullary are observed with essentially an improvement in cortical oxygenation. Thus the discrepant results reported so far with various blockers of the renin-angiotensin system may be explained not only by the duration of administration (acute versus chronic) but also by differences in the methodological evaluation of renal tissue oxygenation. From our data it appears that the analysis with 12 layers within the entire kidney provides more information and is therefore more sensitive to evidence small changes over time. 


\section{Kidney Blood Pressure Research}

Kidney Blood Press Res 2015;40:542-554

\begin{tabular}{l|l}
\hline DOI: $10.1159 / 000368530$ & (C) 2015 S. Karger AG, Basel
\end{tabular}

Published online: October 26, 2015

www.karger.com/kbr

Earlier studies have actually demonstrated that blockade of the renal renin-angiotensin system in experimental studies as well as in hypertensive patients is associated with an increase in blood flow both in the medulla and in cortex with often a greater effect on the medulla [37]. Thus candesartan increases cortical and medullary flow by almost $25 \%$ in control rats [37]. Our observation would be compatible with a similar phenomenon with a greater effect on the cortex. In our study renal plasma flow was actually measured but unfortunately our technique did not enable to perform a separate analysis of cortical and medullary flows. Interestingly our data show that after furosemide administration there is an improvement in cortical oxygenation and an even greater increase in medullary oxygenation in the aliskiren group. This observation is in line with an increased natriuretic response to furosemide when the renin-response to the natriuresis is blocked by the direct renin inhibitor.

The effect of diuretics on renal tissue oxygenation has also been poorly investigated in humans in particular during chronic treatment. As mentioned earlier the renal tubular transport of sodium is one of the highest oxygen consuming processes in the kidney. Thus decreasing sodium reabsorption should be accompanied by a reduction in oxygen consumption and an increase in tissue oxygenation. This has been well documented with the acute administration of furosemide. However, no information exists on the impact of thiazide diuretics on renal oxygenation in humans. In dogs, Thurau et al. showed that renal oxygenation improved upon administration of a thiazide [30]. In animals, acetazolamide, a proximal diuretic, has been shown to increase cortical oxygenation and to reduce medullary oxygenation [38]. In patients chronically treated with furosemide a blunted response to the acute dose of furosemide has been reported [32]. In our study BOLD-MRI was performed before and after 8 weeks of HCTZ 25 mg. Interestingly HCTZ did not increase renal cortical or medullary oxygenation as observed with furosemide and the response to acute furosemide was unchanged. In contrast, we found a significant upward shift of the entire curve in patients treated with HCTZ. This suggests that HCTZ induced an overall decrease in renal tissue oxygenation when this latter is measured $24 \mathrm{~h}$ after dosing. This surprising finding could be explained by a significant compensatory increase in sodium reabsorption at the end of the dosing interval. In this respect it is important to note that BOLD-MRI was performed about $30 \mathrm{~h}$ after the last dose of HCTZ. Thus, patients may be in a sodium retaining phase which is characteristic of a short term withdrawal of a thiazide diuretic. A marked increase in sodium reabsorption would be associated with an increased oxygen consumption and hence a reduction in tissue oxygenation.

This hypothesis is actually supported by our assessment of proximal sodium reabsorption using the endogenous lithium clearance technique which shows a significant reduction in FELi indicating an increased reabsorption of sodium in the proximal segments of the nephron. This probably illustrates a proximal compensatory mechanism to the natriuretic effect of the thiazide diuretic.

During the study, some patients responded to therapy with a marked decrease in their BP. The impact of BP per se on renal oxygenation is not well documented. For this reason we examined the changes in R2* in BP responders and non responders. Despite the relatively small number of patients (12 non-responders; 8 responders including 4 patients under aliskiren and 4 under HCTZ) we observed that a BP response was associated with a significant increase in renal cortical oxygenation independently of the treatment modality. A significant correlation was actually found between the change in BP between week 0 and week 8 and the changes in R2* confirming the effect of BP on R2* independently of the type of treatment. This suggests that BP changes have an impact on cortical oxygenation with an improvement of cortical oxygenation as BP is lowered.

Our study has some obvious limitations. The first is the sample size which is at the limit of the statistical power. This may have limited our ability to find significant differences between groups. Because of the small number of patients enrolled, some baseline characteristics were imbalanced but as patients were also their own control in the pre-post 


\section{Kidney Blood Pressure Research}

Kidney Blood Press Res 2015;40:542-554

\begin{tabular}{l|l}
\hline DOI: $10.1159 / 000368530$ & (c 2015 S. Karger AG, Basel \\
\hline
\end{tabular}

Published online: October 26, 2015

www.karger.com/kbr

Vakilzadeh/Muller/Forni/Milani/Hoffman/Piskunowicz/Maillard/Zweiacker/Pruijm/ Burnier: Renin Inhibition and Renal Oxygenation

analysis, we think that this had only a minor impact on our comparison of the 2 drugs. Yet, patients of the aliskiren group were older and had more diabetes, dyslipidemia and coronary artery disease. Hence these patients might have had a different baseline renal oxygenation and might have been less sensitive to the hemodynamic effects of aliskiren. In support of this hypothesis, the $\mathrm{R} 2 *$ values measured in patients of the aliskiren group at week 0 were higher suggesting a lower oxygenation (figure 2). Yet, one does not know what impact these differences in characteristics could have on renal tissue oxygenation. As far as we know, there are no data on the impact of dyslipidemia on renal oxygenation. Regarding the prescription of beta-blockers and calcium channel blockers, similar compounds were used in the 2 groups. Nonetheless, one cannot exclude that beta-blockers could have blunted the changes induced by aliskiren or HCTZ.

There were also slight differences in urinary sodium excretion at week 8 with an increase in sodium excretion in patients on HCTZ suggesting an increased input. However, the differences were small and the inter-individual variability is so high that it is difficult to draw firm conclusions on these differences. In our opinion, the increase in urinary sodium excretion after 8 weeks of HCTZ when patients are on steady state reflects a compensatory mechanism with an increase in sodium intake rather than the natriuretic effect of HCTZ. Among the strengths of our study one should note the design with patients randomly assigned to aliskiren or HCTZ in a single blinded protocol. Moreover, the use of an analytic method which is less investigator-dependent and more reproducible than the classical region of interest method is certainly an advantage that increased our ability to find differences between groups. Indeed this technique is more sensitive to small changes in renal R2* values since a much larger renal surface is analyzed per subject.

\section{Conclusion}

This is the first study to compare the impact of a direct renin inhibitor and a thiazide diuretic on renal tissue oxygenation in hypertensive humans. Our data show that there is no significant difference in renal tissue oxygenation between the aliskiren and the HCTZ groups at week 8. Yet, with a new method of analysis which takes into account the entire kidney, within group analyses suggest that sustained renin inhibition slightly improves renal cortical oxygenation even $30 \mathrm{~h}$ after the last administration, an effect which is definitively not observed in patients receiving the thiazide diuretic who rather exhibit a significant decrease in renal oxygenation at trough. The discrepant results on renal tissue oxygenation obtained previously with blockers of the renin angiotensin system may be due to the method of assessment of renal oxygenation and our new analytic method using 12 layers within the entire kidney should be considered in future studies as it may provide more information on the effects of drugs on kidney oxygenation.

\section{Disclosure Statement}

The authors of this manuscript state that they do not have any conflict of interests and nothing to disclose.

\section{Acknowledgements}

The study was supported by a research grant from Novartis AG, Switzerland. The study was also supported by a grant of the Swiss National Fund (SNF 32003B-149309 to M Burnier). 


\section{Kidney \\ Blood Pressure Research}

Kidney Blood Press Res 2015;40:542-554

\begin{tabular}{l|l}
\hline DOI: $10.1159 / 000368530$ & C 2015 S. Karger AG, Basel
\end{tabular}

Published online: October 26, 2015

www.karger.com/kbr

\section{References}

1 Klag MJ, Whelton PK, Randall BL, Neaton JD, Brancati FL, Stamler J: End-stage renal disease in AfricanAmerican and white men. 16-year MRFIT findings. JAMA 1997;277:1293-1298.

2 Klahr S, Levey AS, Beck GJ, Caggiula AW, Hunsicker L, Kusek JW, Striker G: The effects of dietary protein restriction and blood-pressure control on the progression of chronic renal disease. Modification of Diet in Renal Disease Study Group. N Engl J Med 1994;330:877-884.

3 Jafar TH, Stark PC, Schmid CH, Landa M, Maschio G, de Jong PE, de Zeeuw D, Shahinfar S, Toto R, Levey AS; AIPRD Study Group: Progression of chronic kidney disease: the role of blood pressure control, proteinuria, and angiotensin-converting enzyme inhibition: a patient-level meta-analysis. Ann Intern Med 2003;139:244-252.

4 Navar LG: The role of the kidneys in hypertension. J Clin Hypertens (Greenwich) 2005;7:542-549.

5 Benigni A, Cassis P, Remuzzi G: Angiotensin II revisited: new roles in inflammation, immunology and aging. EMBO Mol Med 2010;2:247-257.

6 Schachinger H, Klarhofer M, Linder L, Drewe J, Scheffler K: Angiotensin II decreases the renal MRI blood oxygenation level-dependent signal. Hypertension 2006;47:1062-1066.

7 Cowley AW, Jr., Abe M, Mori T, O'Connor PM, Ohsaki Y, Zheleznova NN: Reactive oxygen species as important determinants of medullary flow, sodium excretion, and hypertension. Am J Physiol Renal Physiol 2015;308:F179-F197.

8 Evans RG, Head GA, Eppel GA, Burke SL, Rajapakse NW: Angiotensin II and neurohumoral control of the renal medullary circulation. Clin Exp Pharmacol Physiol 2010;37:e58-69.

9 Mori T, Ogawa S, Cowely AW, Jr., Ito S: Role of renal medullary oxidative and/or carbonyl stress in saltsensitive hypertension and diabetes. Clin Exp Pharmacol Physiol 2012;3:125-131.

10 Pedersen M, Dissing TH, Mørkenborg J, Stødkilde-Jørgensen H, Hansen LH, Pedersen LB, Grenier N, Frøkiaer J: Validation of quantitative BOLD MRI measurements in kidney: application to unilateral ureteral obstruction. Kidney Int 2005;67:2305-2312.

11 Prasad P, Li LP, Halter S, Cabray J, Ye M, Batlle D: Evaluation of renal hypoxia in diabetic mice by BOLD MRI. Invest Radiol 2010;45:819-822.

12 Prasad PV: Evaluation of intra-renal oxygenation by BOLD MRI. Nephron Clin Pract 2006;103:c58-65.

13 Prasad PV, Edelman RR, Epstein FH: Noninvasive evaluation of intrarenal oxygenation with BOLD MRI. Circulation 1996;94:3271-3275.

14 Prasad PV, Epstein FH: Changes in renal medullary p02 during water diuresis as evaluated by blood oxygenation level-dependent magnetic resonance imaging: effects of aging and cyclooxygenase inhibition. Kidney Int 1999;55:294-298.

15 Prasad PV, Priatna A, Spokes K, Epstein FH: Changes in intrarenal oxygenation as evaluated by BOLD MRI in a rat kidney model for radiocontrast nephropathy. J Magn Reson Imaging 2001;13:744-747.

16 Hofmann L, Simon-Zoula S, Nowak A, Giger A, Vock P, Boesch C, Frey FJ, Vogt B: BOLD-MRI for the assessment of renal oxygenation in humans: acute effect of nephrotoxic xenobiotics. Kidney Int 2006;70:144-150.

17 Simon-Zoula SC, Hofmann L, Giger A, Vogt B, Vock P, Frey FJ, Boesch C: Non-invasive monitoring of renal oxygenation using BOLD-MRI: a reproducibility study. NMR Biomed 2006;19:84-89.

18 Pruijm M, Hofmann L, Vogt B, Muller ME, Piskunowicz M, Stuber M, Burnier M: Renal tissue oxygenation in essential hypertension and chronic kidney disease. Int J Hypertens 2013;2013:696598.

19 Textor SC, Gloviczki ML, Flessner MF, Calhoun DA, Glockner J, Grande JP, McKusick MA, Cha SS, Lerman LO: Association of filtered sodium load with medullary volumes and medullary hypoxia in hypertensive African Americans as compared with whites. Am J Kidney Dis 2012;59:229-237.

20 Textor SC, Glockner JF, Lerman LO, Misra S, McKusick MA, Riederer SJ, Grande JP, Gomez SI, Romero JC: The use of magnetic resonance to evaluate tissue oxygenation in renal artery stenosis. J Am Soc Nephrol 2008;19:780-788.

21 Gloviczki ML, Lerman LO, Textor SC: Blood oxygen level-dependent (BOLD) MRI in renovascular hypertension. Curr Hypertens Rep 2011;13:370-377. 


\section{Kidney \\ Blood Pressure Research}

Kidney Blood Press Res 2015;40:542-554

\begin{tabular}{l|l}
\hline DOI: $10.1159 / 000368530$ & C 2015 S. Karger AG, Basel
\end{tabular}

Published online: October 26, 2015

www.karger.com/kbr

22 Pruijm M, Hofmann L, Piskunowicz M, Muller ME, Zweiacker C, Bassi I, Vogt B, Stuber M, Burnier M: Determinants of renal tissue oxygenation as measured with BOLD-MRI in chronic kidney disease and hypertension in humans. PloS one 2014;9:e95895.

23 Mancia G, Fagard R, Narkiewicz K, Redón J, Zanchetti A, Böhm M, Christiaens T, Cifkova R, De Backer G, Dominiczak A, Galderisi M, Grobbee DE, Jaarsma T, Kirchhof P, Kjeldsen SE, Laurent S, Manolis AJ, Nilsson PM, Ruilope LM, Schmieder RE, Sirnes PA, Sleight P, Viigimaa M, Waeber B, Zannad F; Task Force Members: 2013 ESH/ESC Guidelines for the management of arterial hypertension: the Task Force for the management of arterial hypertension of the European Society of Hypertension (ESH) and of the European Society of Cardiology (ESC). J Hypertension 2013;31:1281-1357.

24 Pruijm M, Hofmann L, Zanchi A, Maillard M, Forni V, Muller ME, Wuerzner G, Vogt B, Stuber M, Burnier M: Blockade of the renin-angiotensin system and renal tissue oxygenation as measured with BOLD-MRI in patients with type 2 diabetes. Diabetes Res Clin Pract 2013;99:136-144.

25 Manotham K, Ongvilawan B, Urusopone P, Chetsurakarn S, Tanamai J, Limkuansuwan P, Tungsanga K, EiamOng S: Angiotensin II receptor blocker partially ameliorated intrarenal hypoxia in chronic kidney disease patients: a pre-/post-study. Intern Med J 2012;42:e33-e37.

26 Siddiqi L, Hoogduin H, Visser F, Leiner T, Mali WP, Blankestijn PJ: Inhibition of the renin-angiotensin system affects kidney tissue oxygenation evaluated by magnetic resonance imaging in patients with chronic kidney disease. J Clin Hypertens (Greenwich) 2014;16:214-218.

27 Djamali A, Sadowski EA, Muehrer RJ, Reese S, Smavatkul C, Vidyasagar A, Fain SB, Lipscomb RC, Hullett DH, Samaniego-Picota M, Grist TM, Becker BN: BOLD-MRI assessment of intrarenal oxygenation and oxidative stress in patients with chronic kidney allograft dysfunction. Am J Physiol Renal Physiol 2007;292:F513-F522.

28 Epstein FH: Oxygen and renal metabolism. Kidney Int 1997;51:381-385.

29 Welch WJ: Intrarenal oxygen and hypertension. Clin Exp Pharmacol Physiol 2006;33:1002-1005.

30 Thurau K: Renal Na-reabsorption and 02-uptake in dogs during hypoxia and hydrochlorothiazide infusion. Proc Soc Exp Biol Med 1961;106:714-717.

31 Pruijm M, Hofmann L, Maillard M, Tremblay S, Glatz N, Wuerzner G, Burnier M, Vogt B: Effect of sodium loading/depletion on renal oxygenation in young normotensive and hypertensive men. Hypertension 2010;55:1116-1122.

32 Hall ME, Rocco MV, Morgan TM, Hamilton CA, Edwards MS, Jordan JH, Hurie JB, Hundley WG: Chronic diuretic therapy attenuates renal BOLD magnetic resonance response to an acute furosemide stimulus. J Cardiovasc Magn Reson 2014;16:17.

33 Piskunowicz M, Hofmann L, Zuercher E, Bassi I, Milani B, Stuber M, Narkiewicz K, Vogt B, Burnier M, Pruijm M: A new technique with high reproducibility to estimate renal oxygenation using BOLD-MRI in chronic kidney disease. Magn Reson Imaging 2015;33:253-261.

34 Burnier M, Rutschmann B, Nussberger J, Versaggi J, Shahinfar S, Waeber B, Brunner HR: Salt-dependent renal effects of an angiotensin II antagonist in healthy subjects. Hypertension 1993;22:339-347.

35 Tocci G, Volpe M: End-organ protection in patients with hypertension: focus on the role of angiotensin receptor blockers on renal function. Drugs 2011;71:1003-1017.

36 Norman JT, Stidwill R, Singer M, Fine LG: Angiotensin II blockade augments renal cortical microvascular p02 indicating a novel, potentially renoprotective action. Nephron Physiol 2003;94:p39-p46.

37 Welch WJ, Baumgartl H, Lubbers D, Wilcox CS: Renal oxygenation defects in the spontaneously hypertensive rat: role of AT1 receptors. Kidney Int 2003;63:202-208.

38 Kusakabe Y, Matsushita T, Honda S, Okada S, Murase K: Using BOLD imaging to measure renal oxygenation dynamics in rats injected with diuretics. Magn Reson Med Sci 2010;9:187-194. 